\title{
EL ATMOTERRORISMO BUROCRÁTICO
}

\author{
Sonia Montecino ${ }^{1}$
}

Me han expulsado la poderosa forma pajaril y su amplio despliegue en la ciudad. Después de tanto esfuerzo he perdido el hilo razonable de los nombres y se han desbandado todas mis historias.

Diamela Eltit, Vaca sagrada, 1991, pág. 11

\section{Declaración de principios}

¿Cómo abordar una indagación sobre los efectos del golpe de Estado de 1973, y la consecuente intervención militar, en la Universidad de Chile sin rozar la historia personal —que sabemos no es más que parte del torrente social—, sin la propia subjetividad envuelta en los marasmos de ese aterrador suceso? Todos(as) fuimos protagonistas de esa marca, incluso los(as) que no habían nacido porque ella, de un modo u otro, está latente en los murmullos de la transmisión transgeneracional del trauma, incluso en el "desbande" de las historias, y en el olvido de los nombres.

No puedo si no hacer comparecer, antes de iniciar este texto, mi propia experiencia que da cuenta de las múltiples y entreveradas imbricaciones a partir de las cuales todos(as) quienes pertenecemos a esta "comunidad" Universidad de Chile fuimos tocados, golpeados, remecidos a causa de esa "expulsión de la forma pajaril". Las tramas de ese momento clave del devenir nacional, además de afectar(nos) en lo político, económico y social, trastocó nuestras subjetividades estrechamente interconectadas por lazos de parentesco, de amistad, discipulares y emocionales. Mi padre fue corroborado como vicerrector de la Sede Arica después del Golpe, fue contrario a la Unidad Popular y vivió todos los conflictos políticos previos a él como profesor en esa sede. El primer tiempo que ejerció su cargo exoneró, como fue común, a un grupo de profesores(as), entre ellos al poeta Óscar Hahn, como se aprecia en el decreto $\mathrm{N}^{\circ} 16.792$ del 13 de diciembre de 1973 y en el No17.284 del 28 de diciembre del mismo año². Teniendo en mis manos

1. Antropóloga, Doctora en Antropología por la Universidad de Leiden (Holanda). Profesora titular del Departamento de Antropología, vicerrectora y Premio Nacional de Humanidades y Ciencias Sociales, 2013.

2. La instrucción de estos sumarios de destitución se asentaban entre otras consideraciones en: "d) El imperativo de lograr una docencia objetiva y pluralista; evitar el uso de la función universitaria con fines proselitistas y sectarios; exigir el cumplimiento efectivo de los planes y programas propios de la función universitaria; e imponer el cabal cumplimiento de las obligaciones y deberes que conlleva la calidad de funcionario de la Universidad de Chile". 
esos papeles, quise incorporar este infortunado hecho y recordé haber conocido hace mucho tiempo al poeta y hablado con él sobre el tema, pero "desbandada" la historia, no pude reconstruir el diálogo y tratando de recuperarlo le escribí:

\section{¡iReanuda conversación de casi 40 años!! (30 de julio, 2013)}

Estimado Oscar, hace casi 40 años tuvimos una conversación respecto a lo sucedido en Arica con tu detención y exoneración de la $U$, tengo recuerdos borrosos sobre las palabras exactas, pero recuerdos emocionales claros: mi padre estuvo envuelto en uno de esos episodios y yo, que estuve en la vereda de enfrente de sus posturas tenía sentimientos contradictorios, como es evidente. Eso me dice mi memoria emocional, que no es más que el inconsciente funcionando hoy día.

Estoy coordinado un libro sobre los efectos del Golpe en la Universidad de Chile (jnada es casual!) que tendrá una parte ensayística (son cinco textos de profesores como Rodrigo Baño, Pablo Ruiz Tagle, Sergio Rojas, Ennio Vivaldi y María Olivia Mönckeberg), otra de investigación con los sumarios desde el 73 al 80, y una de historia oral con entrevistas. Aparte de la coordinación estoy escribiendo e indagando en los sumarios y por eso te escribo, porque me gustaría tener un testimonio tuyo de lo que fue tu experiencia. Lo que yo encontré es un decreto de cesación de tu cargo, junto a dos personas más.

Creo que sería muy importante contar con tu recuerdo, estoy pensando en algo breve, una $o$ dos carillas.

Mi biografía está atravesada por el Golpe y la U (estudié en el Manuel de Salas, en Antropología en la $U$ y he hecho toda mi carrera en ella), por mi padre en esta institución, y por mi hermano que fue también exonerado el 76 porque era comunista (tengo su testimonio y su sumario).

Como ves, para mí sería extraordinario valor tu participación en este proyecto. De antemano gracias por tu amabilidad, cariños de Sonia

p.s. te recuerdo que nos conocimos en el taller de poesía de Enrique Lihn

2 de agosto, 2013

Estimada Sonia:

Después de leer tu email, mi memoria se pegó un salto de 40 años y se me vinieron a la mente algunas imágenes borrosas. Recuerdo a una niña de unos 20 años con la cual conversé del tema Arica y que era hija de Max Montecino. En las décadas siguientes, todos esos hechos empezaron a desaparecer de mi memoria inmediata. Esa es una parte de la historia. La otra es que, al regresar a Chile y establecerme aquí, me topé con el nombre Sonia Montecino, antropóloga y profesora de la "U", en algunas publicaciones o alusiones de amigos. Pero jamás te asocié con esa niña del remoto pasado. Cuando lo mencionaste me pareció notable. 
Ahora me dices que estás haciendo un libro sobre el golpe y la Universidad. Me habría gustado ayudarte, pero no puedo hacerlo por dos razones: al escribir esas dos nuevas páginas tendría que revivir muchas cosas a las que no quiero volver, y además, en estos mismos momentos estoy de cabeza en mi nuevo libro de poemas. Siempre que trabajo en mis versos, distraerme en otros tipos de textos termina afectando mis poemas. A lo mejor son manías, pero es lo que siento. Sin embargo, como una modesta forma de colaborar contigo, te cuento que hay un libro que quizás podrías consultar. Se llama "Qué estaba haciendo el 11 de septiembre de 1973". Es de Roberto Merino y Matías Rivas. Lo publicó LOM hace años, pero no lo tengo. Son artículos de diferentes personas. Ahí hago un relato de mi encarcelamiento en Arica. También está "Conversaciones con la poesía chilena" de Juan Andrés Piña. Tampoco lo tengo y me acuerdo poco de lo que dije. Creo que ahí hablo del tema Universidad-Arica.

Me alegra mucho saber que esa joven con la cual conversé hace siglos, ahora es una distinguida escritora y respetada intelectual universitaria.

Te saluda con especial afecto,

Oscar Hahn

"Tendría que revivir muchas cosas a las que no quiero volver". Yo tampoco quisiera regresar a ese minuto en que Oscar Hahn está sufriendo y en que mi hermano fue objeto de la razzia que ocurrió en el Instituto Pedagógico, cuando fue obligado a renunciar a su calidad de ayudante del Departamento de Geografía; su causa: ser militante del Partido Comunista ${ }^{3}$.

"Después del Golpe, fuimos al Pedagógico y algunos profesores se jugaron por nosotros, nos dijeron a varios ayudantes meritantes a los que nos faltaba terminar las tesis, que finalizáramos, que ellos nos ayudarían. Recuerdo a Claudio Meneses y a otro de apellido Henríquez. Pero también me acuerdo de uno, Sepúlveda, que me denunció y a una mujer que le decían La Peinetita — creo era la esposa de un militar-, ellos nos hostilizaban, y nos decían: 'A fin del semestre deben terminar la tesis, si no los echamos a patadas', del semestre quedaba bien poco. Era una forma de amedrentarnos. Me acuerdo que entre nosotros estaba Ángela Jeria, la mamá de la presidenta. El regreso fue muy duro porque los que pertenecíamos a los distintos bandos políticos

3. No ha sido posible encontrar aún el decreto de su renuncia voluntaria, en su hoja de vida aparece como ayudante meritante hasta el 31-7-74 (expediente 17538) y en un documento de mayo de 1979, cuya referencia es el envío de una fotocopia, se lee: "Expediente sin número, de 1974 de la Facultad de Ciencias Humanas. De: Fiscal General de la Universidad de Chile. A: Decano de la Facultad de Ciencias Humanas. Señor Decano: Adjunto, sírvase encontrar fotocopia de resolución dictada con fecha 8 del presente, correspondiente a sumario ordenado instruir en conformidad a lo establecido en el Decreto 8731 en el Departamento de geografía de esa Facultad y que afectó, entre otros, a don Maximiliano Montecino Aguirre. Sírvase dar cumplimiento a lo ahí resuelto. Julio Salas Romo, Fiscal General". Mi padre, junto a otros vicerrectores de sedes y decanos de la Sede de Valparaíso, presentó (ironías de la vida) su renuncia no voluntaria el 20 de enero de 1981 (decreto $N^{\circ} 1170$ ) cuando asumió como rector delegado Alejandro Medina Lois. 
nos volvimos a encontrar de nuevo, era un clima muy tenso, de mucho miedo porque sabíamos cómo iban cayendo los compañeros. Me dediqué a terminar la tesis, pero en marzo de 1974 llegó una notificación a la casa de mi madre. Se trataba de un sumario: debía ir a declarar al Pedagógico, la fiscal era una profesora de apellido Mardones y el prorector era de apellido Illanes. Mi papá se enteró y consultando a los profesores de su generación del Pedagógico, y supongo a las autoridades que conocía, me aconsejó que fuera a declarar. Yo fui a lo que viniera, dispuesto a afrontar cualquier cosa. Estaba lleno de gente declarando, eran grandes listas las que habían pegadas en las paredes. No eran militares los que hacían los sumarios, sino los mismos profesores, solo civiles. Ahí me dijeron: 'Renuncia voluntariamente, si no: te hacemos el sumario y jamás podrás volver a estudiar ni a ser funcionario público, quedarás marcado para siempre'. Bueno, bajo esa amenaza firmé mi renuncia voluntaria y me alejé con mucha tristeza y por completo de la vida universitaria. Diez años más tarde supe que el cargo por el cual sería sumariado era el de 'violentista que se paseaba con armas por el pedagógico'. Años después se me permitió dar el examen de tesis y pude obtener mi título de geógrafo"4.

En marzo de 1974, cuando notificaron a mi hermano, entré a estudiar al Departamento de Antropología. En una pequeña casa de Macul, al lado del Pedagógico, se desarrolló una vida universitaria que estuvo signada por la desconfianza, pero al mismo tiempo por lazos inquebrantables. Todos(as) aquellos(as) que coincidimos en la oposición a la dictadura y nos reconocíamos en ese horizonte, logramos producir nexos entrañables, y crear una esfera de inmunidad ${ }^{5}$ que nos permitió cruzar un poco más gratamente los cinco años de carrera. Conocí, en esa pequeña Casa, los recelos, las arbitrariedades del día a día académico, el uso malicioso de los micropoderes por parte de ciertos profesores, ayudantes, estudiantes y funcionarios. Fui testigo de la instalación de las diversas formas de represión, de disciplinamiento y de entronización de una nueva forma de concebir la Universidad, así como vivencié también la resistencia en pequeños y grandes gestos, los sobresaltos, los rumores (por ejemplo de que vendría un mítico "ejército libertador") y el ser joven en una época en que el ingenio se debía aguzar día a día para combatir la carcelaria vida que se nos imponía y para sobrevivir con dignidad y creatividad en una carrera que asfixiaba por su ramplonería, su falta de espesor reflexivo y crítico y por la mediocridad de la mayoría de sus docentes. Había, claro, unos pocos que animaron nuestra entrega a la Antropología, como Julia Monleón —quien había vivido los horrores de la Guerra Civil española—, que construyó un refugio en su casa para que algunos(as) estudiantes pudiéramos debatir y conocer lecturas proscritas de los programas de los cursos; y, a pesar de su postura política y sus conservadores enfoques teóricos, Carlos Munizaga fue capaz de abrirnos campos temáticos que hicieron posible muchas búsquedas posteriores; Domingo Curaqueo trajo algunos aires mapuche y palabras que más tarde resonarían en las canchas del nguillatun de su

4. Recogí este testimonio de mi hermano en mayo de 2013, dentro del contexto de un cáncer terminal que lo aqueja.

5. En el sentido que Peter Sloterdijk da a este concepto en Esferas I,II y III, Siruela, 2009. 
sitio natal, Roble Huacho. No puedo olvidar a Juan Rivano, que solo estuvo un semestre con nosotros(as) antes que fuera encarcelado; sin sus clases de lógica difícilmente hubiera podido acercarme a la investigación antropológica. Fuera de esas excepciones, el conjunto de profesores(as) y ayudantes eran personas opacas y obsecuentes que no irradiaban ningún entusiasmo por la disciplina, sino todo lo contrario. Mi pasión por la antropología no fue algo que nació en esas aulas de la pequeña casa de Macul, sino en el trabajo de campo y en la discusión que varios compañeros comenzamos a hacer de modo paralelo y autónomo.

En Avenida Grecia, casi esquina con Macul, funcionaba el Café Pushkin, el que tal vez no fue cerrado ni censurado por la ignorancia de los militares que detentaban el poder casi omnímodo de ese barrio simbólico, donde se alojaron las llamadas "termas de Macul". En ese emblemático sitio era posible reunirse en mesas de más de cuatro personas - algo que estaba prohibido en el casino del Pedagógico, custodiado durante años por agentes de seguridad-, no pedían el carnet de identidad, y aunque sabíamos que había siempre "soplones" e infiltrados, podíamos evadirlos, conversar e intercambiar libros y mensajes clandestinos, tejiendo nuestras redes de solidaridad, aunque a veces ello solo implicara mirarnos de una mesa a la otra en la complicidad de pronunciar "Pushkin", bebiendo un mal café.

Por eso, fui testigo de la oscuridad que trae un eclipse de sol, pero también de los rayos que entibiaron ese período. Pensándolo desde hoy nos sirven las palabras de Carlos Fuentes a propósito de una novela de Carlos Franz: “... La advertencia... es que no hay felicidad asegurada, los extremos del mal se manifiestan en la parte demoníaca del ser humano, los del bien en la parte más luminosa de nuestro ser. Pero en el acto final lo que cuenta es la capacidad trágica para asumir el bien y el mal, transfigurándolos en el mínimo de equidad y justicia que nos corresponde"6.

Sin amplios despliegues en la ciudad, olvidados muchos nombres, deshenebrados los antiguos límites que habían permitido volar hacia proyectos imposibles, todos(as), de un modo u otro, en uno u otro cauce del río, estuvimos implicados en la turbulenta corriente que se cristalizó en el 11 de septiembre de 1973. Por ello hablarla, recorrerla, en lo que toca a nuestra Universidad es el imperativo gesto de "descorrer los tupidos velos", no solo para que no suceda más, sino para que surja la elaboración colectiva que permita reconocer las heridas, los tajos, las costras y la justa sutura que solo la comunidad puede hacer de sus actos violentos, de sus quiebres y de la recuperación de la confianza que quizás nos devuelva nuestra antigua fisonomía pajaril. La historia social siempre tiene un visaje personal —eso lo sabemos los(as) antropólogos(as)—, aunque a veces en el parpadeo de las luces se pierda el hilo de los nombres.

6. En México y Chile. Palabra e imaginación, 2013, pág. 18. 


\section{LAS MÚLTIPLES ESCRITURAS DEL ATMOTERROSIMO BUROCRÁTICO}

Escribir sobre cooperación y solidaridad significa escribir, al mismo tiempo, sobre rechazo y desconfianza. El concepto de solidaridad sugiere individuos que están dispuestos a sufrir en representación del grupo más amplio y que esperan que los restantes miembros individuales del mismo hagan otro tanto con ellos... Tanto quien haya aceptado un depósito de confianza y exigido sacrificios como quien de buen grado la haya depositado y las haya realizado conoce la fuerza del vínculo social. Sea la situación de adhesión a la autoridad, odio a la tiranía o un punto medio entre ambos extremos, el vínculo social en sí se considera por encima de toda discusión. Los intentos de sacarlo a la luz del día e investigarlo tropiezan con resistencias. No obstante debe ser objeto de examen. Todo el mundo se ve directamente afectado por la indole de la confianza que le rodea.

Mary Douglas en Cómo piensan las instituciones, 1986, pág. 15

\section{Trazos de una refundación}

Mary Douglas, la antropóloga inglesa, se ocupó de analizar las instituciones y las diversas aristas que entrañan en tanto "máquinas de pensar" incesantes y en tanto productoras de analogías, de lo idéntico, de clasificaciones, y de decisiones de vida o muerte. Pero sobre todo, coloca atención en cómo las instituciones recuerdan u olvidan, qué cosas deciden conservar y cuáles descartar. Es, precisamente, en ese espacio de la memoria institucional, de lo que se rememora y de lo que se oblitera sobre la historia de la intervención militar en la Universidad de Chile, donde se asienta y ancla este texto. La pregunta sobre el efecto del golpe de Estado de 1973 en nuestra institución, cómo afectó su devenir y cómo marcó su presente, puede ser respondida de múltiples maneras, pero es de sentido común y conocido el daño que se produjo al expropiársele su carácter nacional, al amputarle el Instituto Pedagógico y al deshacerse de un sinnúmero de académicos(as) (cf Anales, Na4, Tomos I y II), estudiantes y funcionarios(as) por sus ideas o pensamientos de izquierda, en sus inicios, o por la disidencia respecto a las políticas aplicadas, más tarde.

Desde un punto de vista estructural es más que obvio el arrasamiento, y el cambio en sus cimientos, reflejado nítidamente en la perversa ${ }^{7}$ contradicción de su carácter actual: recibe un mínimo financiamiento del Estado, pero debe asumirse administrativamente como si de este dependiera económicamente; debe autofinanciarse vía los aranceles de los(as) estudiantes y vivir todas las vicisitudes de la economía de mercado, pero comportarse legalmente como una institución del Estado, "compitiendo" en desventaja con las universidades privadas que operan sin ninguna restricción ni dobles contralorías.

7. Entiendo la perversión desde la definición de la RAE como "Perturbar el orden o el estado de las cosas" y como "Viciar con malas doctrinas o ejemplos las costumbres, la fe, el gusto, etc.", y lo perverso también en el sentido de "suma maldad". 
Por otro lado, desde el interior, se percibe un sistema "federado" de facultades que funcionan de manera autónoma en sus decisiones, pero respecto a la distribución de los recursos y algunas otras materias dependen de las autoridades centrales. Cada facultad semeja una totalidad, muchas veces encerrada en sí misma, con fronteras muy acotadas - ¿correlato quizás de una forma de concebir el conocimiento como sitio estanco o permanencia de una historia que emerge en 1973?-, coadyuvando a ello la diseminación espacial que hoy se trata de superar con la noción de campus y que en el pasado conjuntó a las unidades en torno al concepto de "sede". Tenemos la hipótesis que el estatuto de $1981^{8}$ ha sido el soporte para la persistencia de este modo federado, y de un imaginario que instaló una cultura de fragmentación más que de reunión, y de acento en las figuras de los decanos; un trabajo del estatuto que es posible oír en la cultura universitaria de hoy ${ }^{9}$. Esta conjetura se asienta en algunos de los supuestos que estuvieron presentes tras su promulgación, y que se explicitaron en 1982 en el discurso del rector delegado, brigadier general Alejandro Medina Lois, al inaugurar ese año académico:

- “...en que al aproximarse su $140^{\circ}$ aniversario se inicia una nueva etapa de su existencia, acorde al nuevo Estatuto que define la modernización de nuestra Casa de Estudios, conforme al proceso de Institucionalidad que el Supremo Gobierno está implementando en el plano de la Educación Superior...Al dársele a la Facultad el carácter de "Estructura fundamental de la Universidad de Chile" se ha reconocido orgánicamente el positivo valer que representa en cada una de las áreas del conocimiento, a la vez que ha restituido a los Decanos su calidad de autoridad máxima de ellas con organismos de participación académica e indispensable asesoría, para no retornar jamás a un doloroso pasado de politización y asambleísmo, que trastocara los valores y esterilizara su acción, orientándose en cambio a un espíritu y quehacer netamente universitario.

- La implementación de una política de descentralización de atribuciones, funciones y servicios en las Facultades, señala su creciente importancia dentro de la organización universitaria y las posibilidades de una mayor eficiencia, al aumentar su autonomía en coherente armonía con el marco de las políticas generales y normas reglamentarias fijadas por un gobierno central de racionalizada estructura.

- ...Entendemos la competencia como un elemento de superación, que no excluyen en modo alguno la cooperación existente entre las universidades chilenas

8. Fue aprobado por decreto con fuerza de ley, por el Ministerio de Educación, No 153 de 11 de diciembre de 1981, y publicado en el Diario Oficial en enero de 1982.

9. Recordemos que solo en el año 2006 se cambió el estatuto de 1981, dando paso a nuevas formas de pensar(se) la Universidad con grados crecientes de participación (creación de un Senado Universitario) y algunas nociones de sinergia y cruces entre las unidades y disciplinas. Así, el estatuto de 1981 constituyó, durante más de veinte años, un modus operandi que dio tiempo suficiente para instalar una cultura institucional de fragmentación e individualismo, acorde con el modelo de sociedad "moderna y capitalista" que impera hasta hoy y que se refleja en la tecnocracia que rige el quehacer universitario. 
y que se hace realidad a través de la participación en el Consejo de Rectores actual, que esperamos se haga extensivo a las nuevas universidades e institutos profesionales mediante el correspondiente proyecto de ley que en 1981 fuera propuesto por el citado Consejo al Ministerio de Educación... a través de normas aceptadas entre los pares para evitar el caos de un eventual libertinaje ante una excesiva liberalidad"10 (Subrayado nuestro).

Se aprecia en esta cita el carácter fundacional que el régimen militar otorgó al estatuto de 1981 y las bases para el cambio en su gobierno colocando en las facultades y en los decanos un peso institucional autónomo y descentralizado, pero sobre todo un modo de ejercer la autoridad que evitara el "pasado", es decir, la participación de la comunidad universitaria en las decisiones. Todo ello, en vistas a una "eficacia" institucional que le permitiera competir en el nuevo tinglado universitario y de entronización del neoliberalismo ${ }^{11}$.

Estas son los principios históricamente marcados, de acuerdo a nuestra conjetura, de la perversa configuración actual de la Universidad de Chile en el contexto del proceso ya acabado de proliferación de universidades privadas y del proceso general de privatización de la educación (muchas de esas academias privadas se ven actualmente sumidas en el "caos" al que aludía el rector delegado ante la "excesiva liberalidad" y sin normas establecidas contra el libertinaje). La cultura que irrumpe con el Estatuto de 1981 se dejó sentir provocando el resquebrajamiento de los sentidos de una institución que se pensó durante toda su existencia como republicana, pluralista, laica y pública. Sin embargo, la fuerza de su propia historia no pudo ser reprimida por completo, muchas de las "costumbres" y valores institucionales discurrieron por cauces incontrolables. En esa medida, el "acantonamiento" disciplinario, de las facultades y de los grupos de profesores(as), tuvo también otra cara: sirvió para resistir y reproducir microambientes que se autoregeneraban para no perecer en el atmoterrorismo burocrático (que definiremos más adelante) que imperó durante el período de la intervención. Carlos Monsiváis propuso la metáfora del axolot ${ }^{12}$ para definir las identidades mexicanas, y si recuperamos su sentido, podríamos decir que la Universidad de Chile adoptó, después de los 17 años de "ocupación" — metáfora acuñada por Rodolfo Saragoni para definir

10. Discurso de Inauguración del Año Académico el 26 de marzo de 1982, en Anales, No 4, 2013, págs. 228-229.

11. Resulta de enorme valor, para conocer el proceso de transformación que la ideología liberal de mercado emprendió en la Universidad, el libro Economistas de la U. Una biografía, 1934-2009 del Departamento de Economía, Universidad de Chile, 2009. Allí es posible constatar los pormenores de las distintas etapas vividas durante el período de la intervención, que se reflejan en los sumarios que hemos investigado: la primera fase de 1973 a 1980, y la segunda de 1980 a 1990, y cómo el modelo económico instaurado por la fuerza tuvo sus actores relevantes en académicos y autoridades de esa facultad, y por cierto también se aprecian las disidencias y resistencias.

12. La mitología azteca dice que fue gemelo de Quetzalcóatl y recurrió a múltiples transformaciones para escapar del sacrificio, por eso se lo conoce como un dios que rehúye la muerte y se escapa de ella por medio de sus poderes de cambio. Se trata de animales pacíficos, pero a la hora de comer se pueden morder entre ellos hasta arrancarse partes del cuerpo. 
esa época- ${ }^{13}$ y de otros más de recuperación de la democracia, esa misma forma: la de un animal de extraña metamorfosis, que posee branquias y también pulmones, que puede morar en la tierra y bajo el agua, un "animal monstruo", que se niega a desaparecer y que para ello ha desarrollado la habilidad de ser un sobreviviente que respira bajo distintos medios y en diversas condiciones.

\section{La semioscuridad de la memoria}

¿Qué es lo que nuestra Universidad ha deseado conservar de ese largo y complejo período de su historia y de la de Chile? ¿Qué recuerda y bajo que soportes de memoria? ¿Qué ha decidido olvidar? ¿Qué vínculos sociales ha querido colocar por encima de todo? No son fáciles ni están a la mano las respuestas a estas preguntas. Solo encontramos vetas, filos, a veces filamentos de memorias, retazos de recuerdos en el habla institucional ${ }^{14}$. Y ello es comprensible, a la luz de las rendijas que hemos comenzado a abrir, de los "murmullos" que empezamos a sentir desde el momento en que emprendimos, tímidamente, la búsqueda de esos rastros en la revista Anales dedicada a los 170 años de la Universidad de Chile. El miedo ha sido la explicación de varios, en otros el no querer "sacar los trapos sucios" con que se ha arropado el trauma comunitario. Es claro que la institución ha decidido olvidar algo que la coloca frente al quiebre de las confianzas y la solidaridad, que recuerda un actuar oscuro y a veces sórdido de colegas, amigos(as), compañeros(as) y propio, pero que más que nada la sitúa frente a los sucesos que cambiaron para siempre un modo de hacer y existir universitario.

Sin embargo, no todo es omisión, pues los filamentos que emergen en los memoriales de las distintas unidades ${ }^{15}$ dan cuenta de un recuerdo y un homenaje a aquellos miembros que fueron asesinados. También el gesto del rector Jaime Lavados, expuesto en su discurso del 25 de junio de 1991 en el acto de homenaje a los "estudiantes muertos y exonerados" ${ }^{16}$, o el del rector Víctor Pérez con la Placa de Reconocimiento a todo(as)

13. Cf El murmullo de la memoria, Anales de la Universidad de Chile, Tomo I, No 4, 2012.

14. Desde hace mucho tiempo le reitero una pregunta a Francisco Brieva, actual decano de la Facultad de Ciencias Físicas y Matemáticas, que puede remitirse a la conocida frase de Conversación en La Catedral de Mario Vargas Llosa: “¿Dónde fue que te jodiste Zavalita?”, mi interrogación ha sido: “¿Siempre fue así la Universidad de Chile?". Francisco Brieva me ha respondido desde distintas coyunturas, sí y no.

15. Como por ejemplo, en el Campus Juan Gómez Millas, en la Facultad de Medicina, la facultad de Derecho, la Facultad de Economía y el Campus Sur. También se alzo un memorial en la antigua Escuela de Trabajo Social y Enfermería Oriente, en dependencias que actualmente son de propiedad de la Universidad Academia de Humanismo Cristiano.

16. Se plantea allí que: "Al llamado público que hizo nuestra Universidad en julio de 1990, respondieron tanto quienes fueron alumnos de estudios ofrecidos por las actuales facultades, como aquellos que lo fueron de las ex sedes de la Universidad de Chile... esto permitió tratar un total de 391 solicitudes, de las cuales 151 corresponden a la Universidad de Chile, 232 a las Universidades derivadas y 8 reconocimientos o validaciones de títulos... De los 151 casos que corresponden a la Universidad de Chile 79 fueron reincorporados como alumnos exonerados, mientras que los restantes 72 han sido tratados como situaciones de carácter académico o reglamentario". (Anales, No 4, 2013:268-269) 
aquellos(as) académicos(as), estudiantes y funcionarios(as) de la Universidad de Chile y sus familiares que sufrieron de un modo u otro los efectos de la dictadura develada el 11 de septiembre de este año, ponen de manifiesto un deseo de no olvido. Del mismo modo, toda vez que se indaga en la historia oral van surgiendo los relatos de diversos momentos y más tenue o más acentuadamente, cada académico(a), funcionario(a) y ex estudiante de aquella época posee una memoria que no se borra, documentos atesorados, testimonios visuales, anécdotas. Mas, hay que interpelar. No es un recuerdo que fluya, como ocurre con todos los acontecimientos dolorosos de la vida personal: cuando los(as) hermanos(as) dejan de serlo y se convierten en desconocidos(as) que luchan como los axolotl por la comida y por respirar, el desgarro es profundo, y sin duda, se quiere obliterar, borrar, relegar a un espacio lejano de la conciencia.

Sin embargo hay memorias que se sacan de la oscuridad. Existen otros vestigios, otros indicios amparados en las sombras. En el caso que nos ocupa, se trata de memorias que restituyen el doble sentido de la palabra oscuro: en tanto adjetivo y antónimo de luz, y en tanto estado o atmósfera enrarecida, que se despliega en toda su magnitud. Se trata de los documentos escritos, de las materialidades que delatan el día a día del funcionamiento institucional y administrativo: sumarios, compilaciones de oficios, decretos y otros documentos universitarios de mediados del siglo pasado. Es la memoria que se aloja en una bodega subterránea de la Casa Central, depositada en una casi tenebrosa habitación, a la que se accede luego de abrir una puerta de metal — que se encuentra en el piso de baldosas del patio Andrés Bello-y descendiendo por una escala mal iluminada. En la humedad de ese sitio abisal, suerte de entraña del edificio, que en su patrimonialidad condensa la historia de la Universidad de Chile, yacen las grafías, las tipografías, los papeles subrayados, las tachas y las lisas páginas donde quedó anotada una parte considerable del proceso de transformación, de cincelamiento de la Universidad a partir de 1973. La bodega es fría e impregnada de abandono, aunque devela una sutil voluntad de albergar esa memoria, pues los expedientes están ordenados por años ${ }^{17}$.

Entremedio de compilaciones eternas de diarios oficiales, de archivadores mohosos, de libros encuadernados, se apilan en estantes desvencijados los emblemáticos sumarios: instrumento de registro y a la vez de sanción, castigo y relato del miedo, del clima institucional en una organización académica intervenida y "vigilada", usando la frase emblemática de Jorge Millas.

A través de esos documentos, subterráneamente conservados en el vientre de nuestra Casa, y dejados por las autoridades del período, ha sido posible aproximarnos desde otra óptica a la memoria del Golpe y de la intervención militar. ¿Por qué los rectores delegados y su aparato administrativo mantuvieron estas huellas que delatan su actuar

17. Hay que señalar que esta intención fue la del actual director jurídico, Roberto La Rosa, quien trasladó los expedientes que encontró en los Archivos de la Dirección Jurídica en el segundo piso de la Casa Central a la bodega en que nosotras los hallamos. Según sus palabras siempre consideró que esos papeles estaban aguardando "para servir en el futuro" y que quienes no los desecharon o no quisieron deshacerse de ellos, en el pasado, posiblemente habrían pensado lo mismo (conversación personal, agosto del 2013) 
represivo y de quiebre de la Universidad? Tal vez por ese carácter "fundacional" con que asumieron la tarea de cambiar a Chile y traerlo al "orden" (un orden por cierto trazado a fuego por el neoliberalismo como ideología). Tenemos la hipótesis que los sumarios aparecen como definición de límites, y por ello no fueron destruidos y desmantelados de los archivos institucionales. Holzapfel sostiene que:

"Importa destacar la asociación entre límite, delimitación —el acto de delimitar, de fijar y establecer límites con el poder. Fundamentalmente en ello radica el poder: en delimitar. Por este motivo se puede entender en qué medida a la vez la delimitación suele estar ligada a la agresión y violencia" (pág. 20) ${ }^{18}$.

Desde esa perspectiva el instrumento "legal" que define al sumario como "procedimiento que corresponde incoar en todos aquellos casos en que es necesario investigar una infracción administrativa, y no corresponde instruir una Investigación Sumaria en atención a la naturaleza y/o gravedad de ella"19, se utilizó para definir justamente los límites y delimitaciones del proceso que se instalaba y por eso no podían ser destruidos: ellos legitimaban el "orden" que mesiánica y violentamente se imponía en Chile.

Puede aparecer como un contrasentido que los "culpables" — desde el punto de vista de quienes no compartimos su misión "restauradora"- dejen incólume el registro de sus arbitrariedades. ¿Cómo se entiende que los rectores militares y delegados por Augusto Pinochet para intervenir la Universidad, imprimieran sus firmas y sus anotaciones en los decretos y en los sumarios, que quedaran las declaraciones de los inculpados y los testigos en las cuales es posible escuchar mucho más que lo que soporta el papel (como las delaciones abiertas y las encubiertas, la feroz desconfianza de unos(as) con otros(as), el rol de los(as) académicos(as), entre otras cosas)? Creemos que no es casual que estas huellas hayan permanecido. Los rectores delegados dejaron rastros y trazas que podemos interpretar como parte del proceso de disciplinamiento y de "escarmiento" (ellos estaban persuadidos que quizás con ese registro legal de su rigor impreso en las sanciones de los sumarios y decretos "nunca más volvería el marxismo" a la Universidad de Chile y a Chile). Pero más allá de eso, los sumarios operan como siniestros déjà vu, como recordatorios, de lo peor —y a veces de lo mejor - de nosotros(as) mismos(as): un monumento imperecedero de la aplicación de la sanción como fórmula "pedagógica" para mantener el "orden" institucional, para fijar los límites y para "depurar"20. Si en los cuarteles y agencias secretas se torturaba, asesinaba y maltrataba para lograr ese propósito, en la Universidad el sumario emergía como el instrumento ejemplificador ante cualquier desviación de la norma impuesta por los límites del Gobierno Militar. Se trata de la aplicación de la ley y como tal de la "maldición de la ley"21, pero al mismo tiempo de la instalación de una atmósfera de terror.

18. Holzapfel, C., De cara al límite, Santiago de Chile: Ediciones Metales Pesados, 2012

19. Véase http://www.slideshare.net/asesorfenats/normas-relativas-a-investigaciones-y-sumarios-administrativos

20. Este concepto es utilizado por J.J. Brunner en su Informe sobre la educación superior en Chile, FLACSO, 1986.

21. Este término de Ricoeur es reflexionado por Holzapfel, quien sostiene: "Ello quiere decir que la sola ley crea el mal, dado que lo que hasta ahora simplemente fluía y no era considerado malo o negativo en 
Por otro lado, utilizando los términos de Mary Douglas, al permanecer esos sumarios intactos, también se quiso conservar un cierto modo de pensar burocráticamente a la Universidad y a sus componentes. Como parte de la administración pública, los(as) académicos(as), funcionarios(as) y estudiantes son sujetos sumariables, sobre todo dentro de los imaginarios militares donde el cuartel es el non plus ultra de la jerarquía y del acatamiento de las órdenes. Decretos y sumarios permiten rastrear cuáles son los elementos que sirven para deconstruir el período y las formas de concebir la institución por parte del poder. Quizás eso gravitó en que no fueran arrasados por completo ${ }^{22}$, ocultos o quemados (como sí ocurrió en otros casos). Pero, hay más razones: ya hemos hablado del sentido "salvífico" con que se autocomprendían los militares, con el que justificaron sus asesinatos, el quiebre democrático y la instauración de un modelo económico. Es posible que su autoidentidad como redentores les haya permitido un sentimiento de impunidad, encubierto en la "legalidad" de los sumarios y decretos que emitían. Ese disfraz de "justicia", ese remedo de respeto — claramente visible en los expedientes- aparece como la cara más terrible del atmoterrorismo burocrático al que nos referiremos más adelante. Si alguien se piensa a sí mismo como un salvador, no tiene por qué ocultar las huellas de actos que considera parte de su misión como restaurador del orden social en la Universidad que más amenazaba los principios de la Junta Militar. Esta concepción salvadora se ancló en la idea de la "reconstrucción" nacional que incluía a la Universidad de Chile, pues esta, como sostuvo el rector delegado Agustín Rodríguez Pulgar en 1974:

"...-no debemos olvidarlo- fue uno de los blancos predilectos del marxismo y no podía ser de otra manera ya que ella constituye un poderoso medio de influencia ideológica por su carácter nacional y por la incontenible acción multiplicadora que produce la educación. Estamos ahora atravesando la importante etapa de reconstrucción moral y material del país y de nuestra institución. Hemos debido limpiar el terreno de sus ruinas para reedificar nuestra Universidad sobre sus sólidos cimientos que felizmente no fueron alcanzados, gracias a la resistencia heroica y tenaz de ustedes... Hoy más que nunca, la Universidad de Chile (...) debe esforzarse en sus elevados quehaceres para recuperar los años perdidos, y presentar al mundo, a corto plazo, un nuevo rostro, limpio, eficiente y lleno de confianzas en el futuro.... Sin embargo, debemos estar siempre alertas ante los intentos del marxismo que ataca desde dentro y desde fuera del país, apoyado por la poderosa máquina soviética y por los títeres incondicionales diseminados por todas las latitudes de la tierra. Ustedes deberán ser los guardianes para evitar también que la política, en cualquier forma y de cualquier color, vuelva a introducirse en las aulas universitarias" ${ }^{23}$ (Subrayado nuestro).

cualquier forma, lo es desde el establecimiento de cierta ley, norma, precepto, y que se expresa como la prohibición de algo, una conducta, una acción.... mientras más leyes, más mal en el mundo" pág. 20.

22. Hay que señalar, eso sí, que muchos sumarios están perdidos —al menos no aparecen en esta revisión exploratoria-; hemos podido rastrear los decretos (la mayoría de los cuales, afortunadamente, fueron digitalizados desde hace un par de años por la VAEGI), pero en varios casos no encontramos los expedientes correspondientes.

23. Mensaje a la Comunidad Universitaria, del rector delegado Agustín Rodríguez Pulgar, en el $132^{\circ}$ Aniversario de la Universidad, diciembre de 1974, en Anales, Tomo II, No 4, 2013, pág. 180. 
¿Bajo estos predicados no son los sumarios un elemento clave para construir una nueva organización universitaria que administrativamente lograra edificar — disciplinar- sobre las "ruinas" las nuevas ideas de "pureza", de "eficiencia" con los "guardias" (protectores) adecuados? Desde esta mirada esos instrumentos sancionadores y su aplicación, son el ejemplo prístino de la política que los "salvadores" del marxismo querían fundar. Por ello, conservarlos no fue más que el gesto de quienes creyeron estar en lo "correcto", siguiendo las normas y utilizando las herramientas administrativas que la burocracia de la Universidad como institución pública poseía.

Lo que resulta sorprendente es que una vez recuperada la democracia en el país y en la Universidad, nadie haya indagado en estos documentos. Afortunadamente, sin un prurito de protección patrimonial, pero sí con uno de conservar, como ya dijimos, se depositaron las carpetas y expedientes en la antigua y húmeda bodega. Ahí permanecieron hasta ahora ${ }^{24}$. Quizás lo doloroso de las historias que allí aparecen y el hecho de que muchos(as) de sus protagonistas están vivos(as), ejerciendo como académicos(as) y funcionarios(as), impuso una prescripción implícita a su socialización dentro de la comunidad. La conmemoración de los cuarenta años del golpe de Estado, sin embargo, hace difícil postergar la pregunta por sus efectos en nuestra Casa de Estudios. Estos expedientes y su escritura representan la posibilidad de asomarnos a los hechos y comenzar a asumir esta historia poco grata. Subercaseaux habla de los peligros de una "memoria desnuda":

"... que se desentiende de lo que es políticamente adecuado en función del presente, y que en ese sentido es imprudente; aquella que mira no solo un segmento del pasado sino que se arriesga en un campo más amplio; aquella que no es prisionera de lo que pueda acontecer... Si bien este tipo de memoria genera complicaciones para la real politik, también hay que decir que es necesaria, a condición de que no se instale operativamente como una memoria permanente, y menos aún con un espíritu de vendetta a lo Montescos y Capuletos"25.

La advertencia es "políticamente correcta", sin embargo desde el punto de vista de la memoria colectiva lo que "ocurrió" jamás será aprehendido en la "desnudez" porque el recuerdo, mediado por el relato y por las "homeostasis de la memoria" ${ }^{26}$, nunca "es" la realidad. Incluso en los registros escritos de los sumarios siempre están los "restos" no asibles de las subjetividades, aquello que solamente nos llega como rumor y suposición, a veces como indicio y las más como ficción. Ello no obsta el dilema de cómo presentar los datos documentales, icon los nombres y apellidos de todos(as) quienes estuvieron envueltos(as) en los sumarios? Ello podría ser equivalente a esa "memoria desnuda" y a

24. El profesor Bernardo Subercaseaux ha sido uno de los pocos, sino el único que ha sabido de estos registros, como lo sostiene en su ponencia "Memoria posible y memoria desnuda": "La laguna puede ser llenada por la vía de testimonios de quienes fuimos testigos de esa época, y también por la investigación académica y por los cientos de documentos que deben obrar en los sótanos de la Dirección Jurídica de la Universidad" (Ponencia leída en el Seminario sobre la Memoria a propósito de los cuarenta años, organizado por el CECLA de la Facultad de Filosofía y Humanidades, julio 2013, pág. 1).

25. Op. cit., 2013, pág. 2.

26. Goody, J. (ed.), Literacy in Traditional Societies, Cambridge, UK : Cambridge University Press, 1968. 
sus riesgos, sin embargo tras esos nombres están las biografías y, sobre todo, los vínculos sociales que se establecían en la institución "acechada", relaciones que definieron el estado de la organización universitaria y su futuro, así como los papeles de cada quien en una coyuntura histórica crucial. La capacidad de superar el espíritu de vendetta, sin duda pasa — como en las terapias_ - por reconstruir el nudo de la represión del trauma social, hasta conocer sus síntomas, sus iteraciones, sus violencias en las representaciones que permanecen como significantes recurrentes. Sin duda, es doloroso llegar a saber que fuimos parte de una maquinaria burocrática donde ejercimos violencia o fuimos violentados, pero solo enfrentando, elaborando y asumiendo la verdad de nuestros actos (y las reparaciones y justicias necesarias) es cuando podemos re-pensar y propiciar otras formas de ejercer el poder y de confrontarnos a la obligación humana del acuerdo solidario de los límites y de los derechos.

\section{La configuración del atmoterrorismo burocrático. Las cuatro fracturas}

La dimensión de los efectos de la intervención militar en la Universidad de Chile no ha sido estudiada sistemáticamente, no hay registros unificados sobre la cantidad de estudiantes, profesores(as) y funcionarios(as) exonerados(as), sumariados(as), acosados(as), ni de sus miembros desaparecidos o afectados por la represión.

"Aunque no existe una determinación exacta de cuánta fue la gente afectada por las medidas de depuración en el conjunto del sistema universitario, estimaciones globales sostienen que en los primeros meses del régimen militar y durante 1974, se marginó a un 25 por ciento del personal docente, a un 10 por ciento del personal no académico y entre un 15 y un 18 por ciento de los estudiantes"27.

Estos porcentajes corresponden a un universo mayor que el de la Universidad de Chile, y dan cuenta del primer momento de la dictadura, por ello no poseemos un referente estadístico sólido, sino solo las huellas cualitativas que hemos encontrado en los sumarios que elegimos de los estantes de la oscura bodega, y que en este texto mostramos en una ínfima parte (emprender una investigación exhaustiva será materia pendiente $)^{28}$. Sin duda, los escritos aherrojados en la bóveda de la Casa Central dan cuenta de un proceso que estuvo estratégicamente pensado y actuado, y al mismo tiempo documentado a través del papeleo administrativo, oficios, decretos y sumarios. Las improntas y marcas de los sujetos están señaladas en esos papeles, algunos casi desleídos y sus firmas, sus anotaciones estremecen, porque ponen de manifiesto un plan racionalmente formulado.

27. Manuel Antonio Garretón y Hernán Pozo, citados por Economistas de la U..., 2009, pág. 222.

28. Se proyecta construir un "Archivo Universitario" con los documentos encontrados, digitalizarlos en su totalidad para que ellos pasen a formar parte de los acervos del Archivo Central Andrés Bello y puedan ser estudiados y abordados en investigaciones históricas, antropológicas y sociológicas de amplio aliento. La magnitud de los datos y sus contenidos lo amerita. 
De la lectura de cien sumarios ${ }^{29}$ emerge lo que podríamos denominar el "clima" del asentamiento de un nuevo orden en la vida cotidiana de la Universidad. Cada uno de ellos aparece como un microrrelato de las experiencias del día a día, una nouvelle que permite acceder a las circunstancias, los lenguajes, las codificaciones y las angustias de la época; pero también a una cierta "picaresca" — sobre todo muchos relacionados con las persecuciones a los(as) estudiantes por sus desacatos políticos y su creativa resistencia—, a un "bodeville" - la comparecencia de testigos preformateados, por ejemplo-y a un cinismo - las vacancias de cargo a quienes no retornaban a tiempo a su trabajo o no regresaban de sus becas sabiendo que muchos de ellos o estaban presos o habían tenido que exiliarse- - Un estudio en profundidad del conjunto de los sumarios podría arrojar una etnografía completa de la cultura del período, pero sobre todo del ambiente en que se vivía. Tomaremos de Sloterdijk la noción de atmoterrorismo para intentar comprender y al mismo tiempo elaborar una explicación de lo que fueron las relaciones interpersonales y organizacionales durante la intervención militar de la Universidad. El atmoterrorismo está relacionado con lo que el filósofo alemán llama la "guerra del gas" que marcará el siglo pasado:

"En su primera aparición la guerra de gas reunió en estrecho consorcio los criterios operativos del siglo XX: terrorismo, conciencia del design y planteamiento medioambiental. El concepto exacto de terror, presupone, como se ha mostrado, un concepto explícito de medioambiente, porque el terror representa el desplazamiento de la acción destructiva desde el "sistema" (aquí, desde el cuerpo enemigo físicamente concreto) a su 'medioambiente' (en este caso el entorno atmosférico en que se mueven los cuerpos enemigos obligados a respirar)" 30 .

El terrorismo tiene la particularidad de "atentar" no solo por la sorpresa con que actúa sino por "el aprovechamiento maligno de los hábitos de vida de las víctimas... No solo es la desesperación, según observaba Jean Paul Sartre, es un atentado del ser humano contra sí mismo; el atentado al aire del terrorista de gas produce en los atacados la desesperación de verse obligados a cooperar en la extinción de su propia vida, debido a que no pueden dejar de respirar" ${ }^{\prime \prime}$.

Sloterdijk considera el aire y la atmósfera como "medios de vida primarios tanto en sentido físico como metafórico" 32 y es desde ese lugar que formulamos la idea de "atmoterrorismo burocrático" como acción expresada en los sumarios y a ellos en tanto herramienta y signo del terror impuesto en la institución académica.

La Universidad de Chile se ha construido como una de las organizaciones señeras del republicanismo, de la laicicidad, del pluralismo en el saber y en la interpretación de las cosas y el mundo. Como toda organización pública funciona con procedimientos burocráticos, jerarquías, y ritualidades, estableciendo un conjunto de vínculos sociales que la mueven y dinamizan. Uno de los relatos que corresponden a su ritualidad acadé-

29. Calculamos que hay alrededor de 1.000 .

30. Sloterdijk, P., Esferas III, Siruela, 2009, pág. 84.

31. Op. cit., pág. 85

32. Op. cit., pág. 86. 
mica está atravesado por la noción de comunidad universitaria compuesta por tres estamentos: académico, estudiantil y funcionario. La comunidad supone precisamente lazos sociales de confianza, solidaridad y sentido de identidad que proveen y producen un "clima universitario" que hace viable la convivencia y la cooperación de los estamentos que la componen. Previo al Golpe militar, ese "clima" estaba impregnado del conflicto producido por la Reforma Universitaria y por las posiciones divergentes o convergentes de los miembros de la institución respecto a los cambios propuestos por la Unidad Popular. Unas "sedes" —utilizando las denominaciones del período— más cercanas a estos, otras más alejadas o divididas en sus posturas, pero sin duda cruzadas siempre por el acontecer y la contingencia. Dada su propia historia hubiera sido imposible que la Universidad de Chile quedara al margen de la disputa por el destino del país que se daba a todo nivel, pues en ella —y desde su fundación— las vanguardias intelectuales, políticas, científicas y culturales tuvieron su cuna y su desarrollo. No disponemos de abundante material bibliográfico o de recopilaciones de historia oral desde los cuales podamos describir en profundidad lo que fue ese clima tensionado ${ }^{33}$, pero hay indicios testimoniales y algunos fragmentos documentales de lo que implicó para su vida cotidiana:

"La generación que ingresó a la Facultad/de Economía y Negocios/ en 1971 ha dejado vívidos testimonios de lo que fue esa época de pasión y polarización política y social. El actual profesor de la Universidad de California Sebastián Edwards recuerda cómo para un grupo de amigos proveniente de colegios privados - entre los que estaban Jorge Bande, Felipe Montt, Máximo Pacheco_ la Universidad de Chile resultaba enormemente atractiva. Era un mundo diferente al que conocían y el lugar que estaba ideológicamente más cercano a lo que pensaban. Pasaban horas y horas en el viejo edificio de República 'discutiendo, leyendo unas pésimas traducciones de unos malos textos marxistas y aprendiendo a pasos agigantados sobre la vida..." 34 .

La división entre la sede norte como la "sede marxista" y la sede occidente como "refugio" de quienes tenían otra concepción de la economía, sin duda propició un ambiente de rompimiento de la cooperación y división en el cuerpo académico, estudiantil y funcionario.

Bernardo Subercaseaux, por su lado, relata:

"En los años de la Unidad popular la Sede/oriente/ fue en términos políticos —en el contexto de la Universidad y del país - un micromundo. Se la conocía como la Sede Roja; el Quilapayún era una de sus marcas de fábrica... No había prácticamente derecha, la derecha era la Democracia Cristiana... La construcción del sujeto y de la identidad se daban en torno a la pertenencia política. Los comunistas se juntaban con los comunistas, los MAPU con los MAPU... Los comidillos y disputas entre los distintos bandos

33. Aunque estamos conscientes de que existen fuentes documentales y testimoniales que deben ser reunidas, como las que aparecen tanto en la primera como segunda parte de este libro.

34. Economistas de la U..., op. cit., pág. 207. 
eran tan crispados como las que se daban en el país entre los partidarios y enemigos de la Unidad Popular... Un clima, en síntesis, que fue obra común de moros y cristianos"35.

La irrupción del Golpe, y la intervención militar de la Universidad, fue un "atentado"36 a los modos en que la comunidad académica había operado desde su fundación (ello no quiere decir que las transformaciones y las disputas en su interior no hayan existido como lo demuestra el proceso de Reforma Universitaria). Uno de los impactos mayores, y la primera fractura, fue la destitución de las autoridades elegidas y la instauración de la "tradición" de los rectores delegados ${ }^{37}$ nombrados directamente por Augusto Pinochet. Este hecho produce un resquebrajamiento del modelo áurico y aureático de la figura del rector como un intelectual cuyo modelo era Andrés Bello y todos los que le siguieron en el siglo XIX y hasta mediados del XX: hombres de ciencia, grandes humanistas, civiles republicanos. La ruptura con ese símbolo es la primera trizadura. Se erige la sombra de los hombres uniformados ocupando el sillón de Bello; hombres cuyo destino final es el uso de las armas y no el de la pluma ni la probeta. El cuerpo de la comunidad se ve herido con ese cambio violento del poder masculino y en los cimientos mismos de su representación. Por primera vez en la historia de la Universidad de Chile un no-académico, es decir alguien fuera de los estamentos comunitarios, ejerce el poder institucional. Bástenos conocer las atribuciones de estos rectores militares para dar cuenta de esta profunda herida al cuerpo universitario, y que quedaron plasmadas en:

"Lo dispuesto por los decretos leyes No 1, de 11 de Septiembre de 1973, que constituye la Junta de Gobierno de la República de Chile, y № 50, de $1^{\circ}$ de Octubre de 1973, que nombra Rectores Delegados de la misma Junta en todas las Universidades del país, y teniendo presente la necesidad de dotar al Rector Delegado de la Universidad de Chile de recursos legales que le permitan adaptar sus estructuras y servicios a las nuevas condiciones de la realidad nacional y a los postulados de la Junta de Gobierno, ésta ha acordado y dicta el siguiente Decreto ley:

Artículo $1^{\circ}$.- Las disposiciones de este decreto ley se considerarán de carácter especial respecto de toda otra norma jurídica aplicable a la Universidad de Chile y regirán hasta que se dicte una nueva legislación orgánica para esta corporación.

35. "Memoria posible y memoria desnuda", 2013, pág. 3.

36. Sloterdijk nos recuerda que el terrorismo siempre tiene ese carácter de atentado que nos remite a la definición latina attentatum, "tentativa de asesinato", cf. op.cit., pág. 85.

37. El $1^{\circ}$ de octubre de 1973 la Junta Militar emitió el Decreto Ley $N^{\circ}$ 50, mediante el cual en todas las universidades del país se instauraba el gobierno de los rectores-delegados. Fueron nueve rectores delegados en todo el período de la dictadura, seis militares y dos civiles nombrados a fines de los 80 . Los rectores delegados militares fueron: general del aire César Ruiz Danyau (octubre de 1973 - julio de 1974); general de Brigada Aérea, Agustín Rodríguez Pulgar (julio de 1974 - diciembre de 1975); fiscal de la Fuerza Aérea, Julio Tapia Falk (diciembre de 1975 - mayo de 1976); general de división Agustín Toro Dávila (mayo de 1976 - diciembre de 1980); general de Ejército Alejandro Medina Lois (diciembre de 1980 - enero de 1983); y Roberto Soto Mackenney (enero de 1983 - agosto de 1987). Los civiles: el ex decano de la Facultad de Ciencias Económicas José Luis Federici (agosto - octubre de 1987); y el filósofo Juan de Dios Vial (octubre de 1987 a enero de 1990). 
Artículo $2^{\circ}$.- A contar desde la fecha de vigencia de este decreto ley el Rector Delegado de la Junta de Gobierno en la Universidad de Chile cumplirá las funciones y ejercerá las atribuciones que a continuación se indican respecto de todas las sedes, estructuras y organismos de la corporación:

1.- Aquellas a que se refieren el decreto ley $\mathrm{N}^{\circ} 50$, de $1^{\circ}$ de Octubre de 1973, y el decreto supremo $N^{\circ} 1.300$ del Ministerio de Educación, de 3 de Octubre de 1973;

2.- Todas las funciones y atribuciones que la legislación orgánica de la Universidad de Chile y demás leyes, reglamentos y decretos de cualquier naturaleza aplicables a ella, entregan a los Claustros Universitarios, a las autoridades colegiadas y unipersonales de la Corporación y a sus jefaturas de servicios;

3.- Todas las atribuciones y funciones que las leyes, reglamentos y estatutos entregan al Directorio de la Corporación de Televisión de la Universidad de Chile, a su presidente y a su Director General, incluyendo la facultad de modificar los estatutos de esa Corporación;

4.- Todas las atribuciones y funciones que la ley $\mathrm{N}^{\circ} 17.336$ y su reglamento entregan a la Comisión Permanente del Pequeño Derecho de Autor y al Director Ejecutivo del Departamento del Pequeño Derecho de Autor de la Universidad de Chile;

5.- La facultad de resolver sobre todas las cuestiones relativas a la situación del personal de la Universidad de Chile y de su Corporación de Televisión, sobre sus derechos y deberes y la de ejercer sobre este personal amplia potestad disciplinaria; la atribución de declarar que determinados cargos y funciones son de su exclusiva confianza, la de suprimir o crear cargos de planta y de contrata; la de contratar y poner término en forma anticipada a contratos de trabajo, de prestación de servicios y de honorarios; la de suspender de sus funciones al personal con o sin goce total o parcial de remuneraciones por tiempo indefinido y la de trasladarlo a otras reparticiones universitarias en cualquier punto del país por razones de buen servicio. También podrá el Rector Delegado efectuar nombramientos sin sujeción a las reglamentaciones de concursos e imponer obligaciones horarias al personal profesional y de jornada completa que goza de reducciones horarias especiales, salvo cuando se trate de personal remunerado por horas servidas.

6.- La facultad de nombrar a quien lo subrogue en el cargo de Rector; la de nombrar y la de poner término anticipadamente al periodo legal por el cual fue designado el Secretario General y la de establecer regímenes de subrogación entre las demás autoridades y funcionarios.

7.- La facultad de ejercer sobre los estudiantes universitarios amplia potestad disciplinaria incluyendo las de aplicar sanciones de amonestación, suspensión, cancelación de matrícula y expulsión....

Artículo 50: Disuélvese a contar desde la fecha de vigencia de este decreto ley los Claustros Universitarios y demás cuerpos colegiados que contempla el Sistema de Gobierno de la Universidad de Chile; disuélvese, además, el Directorio de la Corporación de Televisión de la Universidad de Chile y la Comisión Permanente del Pequeño Derecho de Autor. 
Artículo $7^{\circ}$ : Facúltase al Rector Delegado para constituir una o más Comisiones que le asesoren en el estudio de las reformas que deban hacerse al Estatuto Legal de la Universidad con el objeto de fijar su estructura y sus regímenes definitivos de administración y gobierno.

Regístrese en la Contraloría General de la República, publíquese en el Diario Oficial e insértese en los Boletines Oficiales del Ejército, Armada, Fuerza Aérea, Carabineros y en la Recopilación Oficial de dicha Contraloría.-

AUgusto Pinochet UGARTE, General de Ejército, Presidente de la Junta de Gobierno.-

JOSE T. MERINO CASTRO, Almirante, Comandante en Jefe de la Armada.-

GUSTAVO Leigh GuZMAn, General del Aire, Comandante en Jefe de la Fuerza Aérea de Chile.-

CESAR MENDOZA DURAN, General, Director General de Carabineros.-

Hugo Castro Jiménez, Contraalmirante, Ministro de Educación Pública.

Saluda Atte. a Ud.- René del Villar L., Subsecretario de Educación"38.

(Subrayado nuestro).

El segundo quiebre es aquel que opera en el cuerpo mismo de la comunidad desmembrándola, expulsando a quienes habían sido sus profesores(as), sus alumnos(as), sus funcionarios(as). La no pertenencia, el desarraigo, la construcción de las categorías opuestas de "amigos" y "enemigos" pasó a formar parte de un horizonte nunca experimentado, pues en los momentos más álgidos del conflicto previo, la Universidad comprendía - parafraseando a Subercaseaux - a "moros y cristianos" bajo un mismo techo, bajo un mismo patio, bajo una misma aula, como parte de la comunidad. El tajo en ese cuerpo es el que trajo consigo un nuevo tipo de vínculo social: la desconfianza, el miedo, la delación, la guettización, el secretismo, que comenzaron a formar parte de la nueva cultura militar-universitaria. La primera escena de este resquebrajamiento la podemos fechar entre 1973 y 1975. Fue, quizás, la más violenta y en la cual como un vendaval maldito los primeros rectores delegados efectuaron una verdadera razzia y emprendieron la re-estructuración de las sedes y de las mallas curriculares, especialmente de las carreras humanistas, de las ciencias sociales y de las artes. Correspondió a este período que el gobierno de la Universidad estuviera en manos de los generales de la aviación Ruiz Danyau, Rodríguez Pulgar y Tapia Falk.

La tercera fractura está dada por la amputación de dos de sus particularidades: su carácter nacional y su antiguo liderazgo en la formación de profesores a través del Instituto Pedagógico. A inicios de la década de los 80, mediante un Decreto con Fuerza de Ley $^{39}$, se decide que la Universidad de Chile debe entregar sus sedes de provincia. Hasta ese entonces contaba con nueve emplazadas en Arica, Iquique, Antofagasta, La Serena,

38. Decreto ley No 111.- Santiago, 29 de Octubre de 1973 Que OTORGA AL RECTOR DELEGADO DE LA JUNTA DE GOBIERNO EN LA UNIVERSIDAD DE CHILE LAS ATRIBUCIONES QUE SEÑALA.

39. El DFL No1 de 1981 que reestructura la educación superior del país. 
Valparaíso, Talca, Nuble, Temuco y Osorno. Este cercenamiento también se le exigió a la Universidad Técnica del Estado (hoy Universidad de Santiago de Chile) y por cierto no a la Universidad Católica —intocada por su carácter "pontificio" — que conservó sus sedes regionales. De ese modo, la presencia, el influjo y el "poder" intelectual de la Universidad de Chile a lo largo del territorio fue el nuevo trabajo de la dictadura en pos de transformarla y restarle potencia. Esto fue un atentado a la fuerza que adquirió la institución, a lo largo de nuestra geografía, desde fines de los 50 y que mantuvo hasta la década del 80. Pero, tal vez, el desgarro más profundo, fue el del desprendimiento del Instituto Pedagógico, uno de los rostros más emblemáticos de la propia historia de la Universidad y uno de los núcleos de irradiación y creación cultural que, desde fines del siglo XIX, aglutinó a la intelectualidad más productiva y reconocida de Chile. Ese patrimonio intangible y "propagador de las luces", como diría Bello, fue arrancado del seno de la Casa de Estudios con otro DFL, ahora el No7 del 17 febrero de 1981 que, en reemplazo del Instituto Pedagógico, crea una "Academia Superior de Ciencias Pedagógicas" que más tarde dará nacimiento (en 1986) a la Universidad Metropolitana de Ciencias de la Educación (UMCE). Pese a los reclamos que suscribieron varios decanos y hasta el propio rector delegado Agustín Toro, el general Pinochet —y su aparataje político- fue implacable. Como expresó el decano de la Facultad de Ciencias Agrarias, Veterinarias y Forestales, en 1984:

"La eliminación o desaparición de la Universidad de Chile constituía la etapa final, culmine de una larga lucha en contra de la concepción del Estado Docente. Se eliminaba así el último vestigio trascendente de educación formal estatal, exigiéndosele, eso sí, una importante participación por la vía de los aportes a las universidades privadas. Creemos realmente ilógico la pretensión de limitar en esta forma la labor educativa del Estado, porque sería solicitarle se desentienda de un aspecto fundamental de la vida nacional, es decir, renuncie a ser Estado"40.

A la luz del devenir, nada de "ilógico" hubo en estas brutales "podas"41 a la Universidad de Chile de su identidad nacional y de la formación de profesores(as). Fue simplemente el corolario de la máquina instalada para consolidar el orden neoliberal y la "modernidad" que entrañaba. El síndrome del miembro amputado aún permanece en las sensaciones de la memoria institucional, como fantasma y como nostalgia, pero también como recuerdo de dolor e impotencia.

El cuarto quiebre, relacionado asimismo con la amputación, se instala ahora con lo que podríamos llamar la devastación de las humanidades, las artes y las ciencias sociales —nítidamente dibujada en los documentos que estudiamos - y que supuso la exacción

40. Garrido, J., en Anales, No 4, 2013, pág. 235.

41. Desde la perspectiva de Zygmunt Bauman, "la cultura moderna es una cultura de jardín... De hecho se define a sí misma, a la naturaleza y a la diferencia entre las dos, por medio de su desconfianza endémica a la espontaneidad y su deseo vehemente de un orden mejor y necesariamente artificial... Desde el punto de vista del diseño, todas las acciones tienen un papel decisivo, mientras que todos los objetos de la acción son o bien facilidades o vienen a ser estorbos. El genocidio moderno, lo mismo que la cultura moderna en general, es el trabajo de un jardinero", en Modernidad y Holocausto, Ediciones Sequitur, 1989, pág. 120. 
del capital cultural y social de esas disciplinas. A cuarenta años de la "ocupación", si hacemos una cartografía de aquellas áreas del saber más dañadas podemos apreciar que sus índices y estándares son menores que los ostentados por las disciplinas y áreas que no fueron tocadas ${ }^{42}$. Ello da cuenta de la magnitud del cercenamiento, pues solo a partir de la década del 90 comienzan tímidamente a renovarse los cuadros académicos en esos campos y recientemente se ha abierto el camino para su despegue ${ }^{43}$. ¿Cuánto tiempo demorará la consolidación de un corpus de académicos(as) que produzca el salto cualitativo, la vanguardia en estas disciplinas dentro del nuevo escenario de entronizamiento de la tecnocracia científica acorde con el modelo de libre mercado?

Cuando sostenemos la idea de exacción del capital cultural de las disciplinas de las humanidades, del arte y de las ciencias sociales, nos referimos al hecho de que estas se asientan en un conocimiento que busca desentrañar las estructuras profundas y los mecanismos que nos constituyen en tanto sujetos sociales, así como las transformaciones permanentes de esas estructuras, y la creación constante de nuevas relaciones, significados e interpretaciones del mundo y de las cosas. El atentado se entiende toda vez que se persiguió destruir sus bases epistemológicas, sus teorías, sus métodos y sus prácticas, no solo expulsando a quienes las cultivaban, sino destruyendo su andamiaje materia e inmaterial (aparatos conceptuales vedados, libros censurados, lenguajes prohibidos, bibliotecas controladas, etc.). En el caso de las denominadas "ciencias duras", estas no fueron interpeladas en la matriz de sus procedimientos, ni en sus teorías, ni en sus experimentos, quizás por esa noción equívoca de que son "neutrales" ideológicamente, y porque la racionalidad del Gobierno militar perseguía los ideales del desarrollo moderno - el "jardín" de Bauman- donde, como es sabido, la ciencia y la tecnología juegan un papel fundamental. Este hecho produjo la construcción de sistemas diferenciados de prestigio académico — las "buenas" y "malas" hierbas, parafraseando al autor — que todavía permanecen en la base de las concepciones actuales de qué modelo "científico" debe dominar la escena académica.

No resulta extraño que en el campus Juan Gómez Millas, donde se albergan las disciplinas más castigadas, emerja una suerte de fantasmática imagen que espejea con el pasado: los encapuchados como "tribu" que cumple el ritual de la violencia y su espiral, réplica en las "fuerzas del orden". Allí donde se quiso "desmalezar" jirones antiguos, en el sentido de desgarros y harapos, parecen querer señalar que hay un debate inconcluso, un análisis no realizado, una memoria soterrada, un daño no resuelto. Desde las salas de algunas de las facultades del campus es posible hacer clases y observar cómo en la esquina de Grecia con Capitán Ignacio Carrera Pinto batallas periódicas se libran entre encapuchados y carabineros, cómo se encienden fogatas y no pocas veces cómo los gases lacrimógenos crean una atmósfera asfixiante. Pasado y presente, como sabemos, van de la mano. El futuro es la incógnita.

42. Como por ejemplo Ingeniería. Cf. la percepción de Rodolfo Saragoni al respecto, en el ya citado Anales, $\mathrm{N}^{\circ} 4,2012$.

43. Me refiero al proyecto Bicentenario de renovación de las Ciencias Sociales, las Humanidades y las Artes impulsado en la agenda del actual rector Víctor Pérez. 
Será desde estos cuatro quiebres que los sumarios configuren el atmoterrorismo burocrático, pasando a formar parte de las armas para el combate de aquellos miembros del cuerpo comunitario que debían ser exterminados por sus ideas (las "malezas" que había que arrancar). Se entiende entonces que una de las acciones claves será "contaminar" el ambiente donde la comunidad construía su pertenencia y cambiar los antiguos vínculos sociales de solidaridad por los de adhesión irrestricta al nuevo modelo ideológico de la dictadura militar. No se trataba ahora del libre debate de las ideas y del respeto a la libertad de cátedra (preciado tesoro de la Universidad de Chile), simplemente se debía acatar un mandato emanado desde el rector delegado y de los decretos que lo legitimaban. El atmoterrorismo burocrático consistía en aplicar las sanciones correspondientes a la desobediencia de los edictos, empleando el sumario como la herramienta más eficaz de ruptura de la fraternidad comunitaria.

Es interesante señalar que el atmoterrorismo burocrático y su consiguiente control del pensamiento fueron de la mano con la vigilancia de los medios reprográficos a través de los cuales se podían diseminar las ideas. Es frecuente encontrar causas sumariales por robo de esténciles, uso de mimeógrafos y otros. Por ello, hubo una inspección férrea sobre los equipos de la Universidad, como consta en el siguiente oficio:

UNIVERSIDAD DE CHILE

$362 / 74$

CAE-fha

REF: Sobre de la disposición del Art. $2^{\circ}$ de la Ley 15.576

OFICIO N $550 /$

SANTIAGO, 25 de Octubre de 1974.

SEÑOR SECRETARIO ABOGADO:

En mi carácter de Asesor Jurídico de la Universidad de Chile y por disposición expresa del Sr. Rector don AGUSTIN RODRIGUEZ PULGAR quien desea hacer cumplir estrictamente en todos los Servicios Universitarios la legislación vigente sobre imprentas, litografías y talleres impresores, me dirijo a Ud. para solicitarle se sirva informar a esta Asesoría sobre el exacto alcance de la disposición del Art. $2^{\circ}$ de la Ley 15.576 que ordena declarar la existencia de equipos de impresión a la Dirección de Bibliotecas, Archivos y Museos. En relación con la amplitud de ese precepto nos asaltan varias dudas que la opinión de la propia Dirección podría ayudarnos a resolver, tales como las siguientes:

1.- ¿los roneos, mimeógrafos y otros equipos comprendidos en la denominación genérica de polígrafos deben declararse?

2.- ¿Deben declararse los equipos de reproducción fotográfica de impresos? ¿Y las máquinas copiadoras de planos?

3.- ¿Es obligatorio declarar los equipos de impresión aunque sólo estén destinados a reproducir documentos de trabajo interno de la Universidad?

Agradeciendo de antemano la información que Ud. pueda proporcionarme sobre estas materias, le saluda atentamente

GALVARINO PALACIOS GOMEZ

Asesor Jurídico

Universidad de Chile 


\author{
AL SEÑOR \\ SECRETARIO GENERAL \\ DE LA DIRECCION DE \\ BIBLIOTECAS, ARCHIVOS Y MUSEOS
}

PRESENTE /

Apenas instaurado el "orden" de los militares dentro de la Universidad, se nombraron fiscales a cargo de diversos tipos de castigos, desde las exoneraciones, las expulsiones, a las cesaciones de cargo. Lo brutal fue que los fiscales eran miembros del cuerpo académico, muchos de los actuarios o secretarios fueron funcionarios y así... En otras palabras: se utilizaron las manos de la propia comunidad para reprimir y condenar a distintas penas a los miembros del cuerpo que se "desviaban" del camino político y moral omnímodamente construido por el Gobierno dictatorial. Es por eso que calificamos la intervención militar en la Universidad de Chile como un momento prolongado de atmoterrorismo burocrático cuyo fin fue crear un clima irrespirable para aquellos(as) que perteneciendo al cuerpo comunitario no estaban de acuerdo con las políticas impuestas, y para producir — a través del terror y sus amenazas - las transformaciones que el modelo neoliberal propiciaba para la educación superior. Podríamos decir que fue un tiempo abyecto, donde diversos actores de la comunidad jugaron papeles de sumisión, cinismo, abuso de poder, obediencia irrestricta a los dictámenes y obsecuencia. Por otro lado, es también un tiempo de resistencias, boicot, sobrevivencia, creación de grupos cerrados-inmunizados, de rumores y chismes. Pero sobre todo es un período donde la solidaridad y la cooperación universitaria se fragmentan, y la división entre profesores, estudiantes y funcionarios crea barreras inter e intraestamentos ${ }^{44}$. Surge la competencia y el individualismo como parte de la cultura universitaria y un "sálvese quien pueda" como horizonte que la sospecha y las suspicacias avalaron como normas de la vida cotidiana.

El uso común del sumario permite entrever la abyección y por cierto las noblezas que también sucedían en el día a día, pero se advierte que primaban más las oscuras maniobras del poder, al menos en los siete primeros años en los cuales posamos nuestras miradas. Hay algo de ahogante en las atmósferas que cada uno de los expedientes

44. Mi propia experiencia como alumna entre 1974 y 1979 da cuenta del clima de permanente recelo, y distancia de los(as) estudiantes con los(as) profesores(as) no solo respecto de sus posiciones políticas, sino de su idoneidad docente y de su desempeño; de las suspicacias con los(as) propios(as) compañeros(as) y los(as) funcionarios(as): una o un soplón podía estar sentado al lado, cualquier miembro de la comunidad era susceptible de convertirse en un(a) "enemigo(a)", visto a la distancia, quizás ha sido el tiempo de mayor politización y polarización, del juego de máscaras infinitas. Tengo la hipótesis que esas huellas no se han borrado y aún se manifiestan en las formas solapadas en las cuales a veces se manifiesta la discordancia respecto a las políticas universitarias, en las campañas de elecciones de las autoridades y en las convocatorias a conversaciones "clandestinas" (fuera de los recintos universitarios) para planificarlas, para que nadie se entere. El atmoterrorismo burocrático se encargó de sumariar a aquellos(as) que se reunían en las aulas o departamentos y tal vez esa memoria no se haya borrado permaneciendo en los pliegues del inconsciente universitario colectivo. 
posibilita escudriñar y es fácil darse cuenta del atentado al cuerpo académico, a su antiguo entorno, a la tolerancia y a la libertad. Allí en el seno mismo de una institución que se había erigido a la par que la nación, el atmoterrorismo burocrático hizo su trabajo de destrucción de los tejidos y los vínculos sociales basados en la confianza y en el respeto al pensamiento y a las distintas posiciones ideológicas. La tecnocracia, la "eficiencia", el "orden", la racionalidad económica y el economicismo serán los valores que se implantarán para lograr una "Universidad perfecta", es decir una contenida en los límites de los decretos y sus sumarios. Por otro lado, el paso del tiempo evidencia la "naturalización" del poder detentado por los rectores delegados y el uso pragmático de los civiles-académicos en el empeño de refundar a la Universidad de Chile. A nadie le podrá caber duda que esta cambió profundamente durante la intervención militar y que el proceso de su fisonomía axolotl se fraguó en ese período ${ }^{45}$.

\section{Las narrativas sumariales}

El contexto dentro del cual pueden comprenderse los sumarios revisados ${ }^{46}$ está presente en lo estipulado por el Decreto 8.732 del 8 de octubre de 1973 emitido por el rector delegado César Ruiz Danyau y que coloca, desde muy temprano, como se aprecia, los límites y normas que deben seguir estas herramientas del atmoterrorismo burocrático:

"REF: Dicta normas sobre substanciación de Sumarios Administrativos y Procedimientos.

DECRETO No. 8.731, SANTIAGO, 8 de Octubre de 1973.

Con esta fecha la Rectoría de la Universidad de Chile ha expedido el siguiente Decreto: VISTOS Y CONSIDERANDO:

1. Las facultades que el Decreto Ley No.50 de 2 de octubre de 1973 de la Junta Militar de Gobierno confiere al Rector Delegado.

2. La existencia de problemas de convivencia dentro de la Comunidad Universitaria derivados del sectarismo político, de la prédica del odio y la violencia y de la propia situación política que imperaba en el resto del país.

45. El propio atmoterrorismo burocrático se encargó de que así sucediera, al atentar simbólicamente contra el medioambiente universitario con su tóxica impronta, hizo posible que el cuerpo comunitario y la organización institucional desarrollaran todo tipo de estrategias para "respirar": tanto en el agua como el aire ese cuerpo fue adecuándose al orden imperante hasta el día de hoy.

46. Nuestro intento asume el carácter de una indagación exploratoria, en la medida que el volumen y la envergadura de los contenidos de los sumarios hace necesaria una investigación en profundidad y con un tiempo adecuado. De ese modo, solo abrimos un campo de investigación que tendrá que ser abordado en una futura historia contemporánea de la Universidad de Chile. Procedimos a seleccionar solamente expedientes desde 1973 a 1980, dentro de los cuales escogimos aquellos relacionados con causas recurrentes y significativas desde el punto de vista de los motivos y de quienes estaban involucrados. La revisión de cien sumarios nos arrojó luces sobre las constantes de los argumentos para sumariar y pistas para el desarrollo de la hipótesis del atmoterrorismo burocrático. En este acápite reproducimos un conjunto de decretos, documentos y sumarios que nos parecen emblemáticos y que se ajustan a las operaciones tipo que se llevaron a cabo, para que los(as) lectores(as) puedan conocer de primera fuente el "género" legal y discursivo de estos registros, así como seguir los diversos procesos que ellos implicaron. 
3. La necesidad de investigar y sancionar serias irregularidades administrativas consistentes en que el Personal Académico y No Académico ha dejado de cumplir las obligaciones y/o violado las prohibiciones que el Título III del Estatuto Administrativo, que se consagra en el DFL No. 338 de 1960, contempla para los Empleados Públicos.

4. La decisión de la Junta Nacional de Gobierno en cuanto a ordenar y reestructurar las actividades académicas, administrativas y estudiantiles, dentro de las Universidades, a fin de impedir de que se repitan las prácticas y hechos atentatorios al cumplimiento de los fines de toda Universidad.

5. El deber de esta Rectoría — dentro del ordenamiento jurídico vigente y consciente de la necesidad de evitar actuaciones injustas o la satisfacción de enemistades personales- de tomar de inmediato las medidas que sean necesarias para garantizar la justicia y la imparcialidad con que deben adoptarse las medidas de reorganización de los Cuadros Permanentes del Personal de la UNIVERSIDAD DE CHILE y del Estamento Estudiantil, y, el imperativo de proceder con la mayor serenidad a regularizar el funcionamiento de esta Casa de Estudios, y producir la tranquilidad necesaria para continuar el desarrollo de sus actividades.

\section{DECRETO:}

Intertanto se dictan normas definitivas sobre el Régimen Disciplinario de alumnos y funcionarios de la Universidad de Chile y de sus organismo dependientes, regirán sobre el particular las medidas y procedimientos que más adelante se detallan; todo ello sin perjuicio de tener presente que los preceptos contenidos en el Título III del Decreto de Fuerza de Ley No. 338, del año 1960, tienen cabal vigencia, dada la calidad de Empleados Públicos que tienen los funcionarios de la Universidad de Chile.

\section{NORMAS GENERALES}

El no cumplimiento de las funciones docentes o administrativas para las que se fue contratado, la substitución total o parcial de los programas vigentes de la asignatura o de las funciones docentes o administrativas por materias o actividades de adoctrinamiento o proselitismo político; la actitud sectaria y proselitista; todo acto personal atentatorio a la convivencia normal de la Comunidad Universitaria inobservancia de los deberes morales; la inconsecuencia de la conducta extrauniversitaria con lo sostenido en la Cátedra, conforme a los programas de estudios vigentes; constituyen infracción gravísimo a las obligaciones y prohibiciones que consagra el referido Título III del DFL No.338, de 1960. Ello no obstante, se aclara que la mera ideología o pensamiento político personal, cualquiera que sea, no es reprochable ni sancionable.

Además de contar del 11 de septiembre de 1973 rigen normas establecidas en los Decretos Leyes que dicta la Junta Nacional de Gobierno, los Ministerios de Defensa, Interior, Justicia y Educación y las disposiciones que establezca el propio Rector de la Universidad.

\section{PROCEDIMIENTO.}

\subsection{Situaciones Públicas y Notorias}

En el caso de Académicos, No Académicos y Estudiantes que, en forma pública y notoria, hayan infringido las prohibiciones y/o dejado de cumplir las obligaciones que el Estatuto Administrativo impone a los Funcionarios Públicos; o, cuya conducta constituya una amenaza a la normal y buena convivencia de la Comunidad Universitaria; las medidas pertinentes serán adoptadas por el ViceRector de Sede, que corresponda, de Oficio o sugerencia escrita y fundada de autoridad unipersonal, de académico responsable y/o del Fiscal designado para la repartición u organismo de que se trate.

El Vice-Rector de Sede, directamente o por medio de la Autoridad Unipersonal de que dependa el afectado o del Fiscal respectivo, notificará al funcionario o estudiante de que se trate, de la situación 
en que se encuentra, antes de adoptar resolución alguna. El afectado tendrá 24 horas de plazo fatal para formular, por escrito y fundamentadamente, los descargos que estime convenientes. Transcurrido dicho plazo, con los descargos presentados o en rebeldía del afectado, el Vice-Rector dictará su resolución o dispondrá que se instruya Sumario, conforme a las pautas que se establecen más adelante.

\subsection{Situaciones Dudosas.}

En todos los demás casos, en que exista duda o no esté clara la actuación o participación del afectado, deberá instruirse Sumario conforme a las siguientes normas.

\subsection{Fiscales}

Se designará para cada Facultad, Departamento de Sede, Repartición o Servicio, uno o más Fiscales que tendrán a su cargo la substanciación y fallo de todos los Sumarios que, conforme a las normas anteriores, deban incoarse en la Facultad, Departamento o Servicio respectivo.

En lo posible, el Fiscal deberá ser Abogado. La designación de Fiscal implica una Comisión de Servicio inexcusable y de inmediata prioridad.

Las Facultades, Departamentos y Servicios Centrales o de Sede, deberán proporcionar al Fiscal, el personal administrativo, oficina y elementos materiales que éste requiera con prioridad a cualquier otra función.

\subsection{Iniciación de Sumario.}

Todo Sumario deberá iniciarse por denuncia de persona responsable, hecha directamente al Fiscal o a la Autoridad Unipersonal que corresponda, la que la transcribirá de inmediato al Fiscal, sin perjuicio de la facultad del Fiscal para proceder de Oficio.

Las denuncias por hechos ocurridos antes del 11 de septiembre de 1973 deberán efectuarse dentro de los 15 días siguientes a la fecha del presente Decreto. Transcurrido dicho plazo sólo se incoará Sumario por disposición expresa del señor Rector, de los señores Vicerrectores, Decanos de Facultades, Directores de Departamentos de Sede, o de Oficio por el Fiscal.

\subsection{Tramitación del Sumario.}

El Fiscal, recibida la denuncia, adoptará las medidas de prevención que estime conveniente, incluso la de suspender de funciones al inculpado sin goce de sueldo.

El Fiscal adoptará todas las medidas necesarias para investigar los hechos denunciados y la responsabilidad del inculpado. Tendrá facultad para citar a todo funcionario universitario y estudiante a primera audiencia. La no comparecencia del testigo se considerará como falta grave a sus obligaciones funcionarias o estudiantiles, y se sancionará como tal.

La investigación no podrá durar más de ocho días contados desde la fecha de la presentación de la denuncia; y, durante la investigación, el Fiscal deberá interrogar al inculpado en la oportunidad y las veces que estime conveniente. La no comparecencia del inculpado constituirá presunción grave en su contra. Este plazo sólo podrá prorrogarse, por una sola vez y por un mismo número de días, por resolución fundada del Fiscal.

Agotada la investigación, con la declaración del inculpado, o en su rebeldía, el Fiscal acusará. El inculpado deberá presentar sus descargos y rendir las pruebas en que se funden, en el plazo fatal de tres días contados desde su notificación.

Presentados los descargos y extinguido el plazo para ello, se dictará la sentencia, sin más trámite.

La sentencia sólo contendrá la indicación de los hechos imputados y la fundamentación somera de la decisión del Fiscal. 


\subsection{Notificaciones}

La citación del afectado y la resolución del Vice-Rector, en el caso contemplado en el Párrafo 2.1 de este Decreto; la citación a declarar, la acusación del Fiscal y el fallo serán notificados personalmente o por cédula que se dejará en el domicilio que el inculpado tenga registrado en la Universidad o en el que éste hubiere señalado expresamente en el Sumario.

\subsection{Apelación.}

Sólo serán apelables las resoluciones y fallos que apliquen las sanciones de la destitución, de petición de renuncia, declaración de vacancia del cargo y suspensión de funciones académicas por plazo superior a seis meses. En el caso de estudiantes, solo será aplicable la resolución o fallo que cancele definitivamente su matrícula o la suspenda por plazo superior a un año.

La apelación deberá ser fundada y se interpondrá por escrito, ante la autoridad que dictó la resolución o fallo respectivo. Los autos se elevarán de inmediato al Tribunal Unico de Apelaciones, que se establece en el párrafo siguiente.

\subsection{Tribunal Único de Apelaciones.}

Conocerá de las apelaciones un Tribunal Único de Apelaciones, que estará integrado por el señor Rector, quien lo presidirá y cuatro miembros de la comunidad universitaria que el señor Rector designará libremente.

Las apelaciones se resolverán en cuenta y sin más trámites, salvo que el Tribunal, expresamente, acuerde otra cosa.

La sentencia del Tribunal Único de Apelaciones no requerirá de fundamentación alguna, salvo el caso que revoque o modifique el fallo apelado. En este evento, sólo se requerirá de una fundamentación somera. El fallo quedará ejecutoriado por el solo hecho de dictarse la sentencia de segunda instancia.

\subsection{Cumplimiento de las Resoluciones y de los Fallos.}

Ejecutoriada que sea una Resolución o Fallo condenatorio, se comunicará dicha resolución o fallo a la Rectoría, a fin de que se dicte el Decreto que proceda, para su cumplimiento.

\section{COORDINACION Y DEPENDENCIA DE LOS FISCALES.}

Los Fiscales serán coordinados y dependerán directamente de un Coordinador General que designará el señor Rector.

Este es el marco en el cual se desarrollan los sumarios y su política de disciplinamiento, escarmiento y contaminación. Los "deberes morales", las materias proscritas (la política y el proselitismo), las conductas "correctas" de los(as) miembros de la comunidad universitaria, son las que reverberan en cada uno de los expedientes. También el cinismo legal que "aclara" que el tener un pensamiento político o "mera ideología personal" no es sancionable. Eso es lo que declara el decreto del General Danyau, pero otra cosa es lo que las propias causas y los documentos evidencian, así como las prácticas "inmorales" que instauraron como la delación, el soplonaje y las denuncias arbitrarias. El decreto señala también nítidamente el modus operandi para los sumarios y es la guía para com- 
prender su dinámica, así como la comparecencia de las autoridades, de los fiscales, de los(as) sumariantes y los sumariados(as).

Desde ese marco se desprenden las causales más reiteradas que se encuentran en los decretos, resoluciones y sumarios, las que podríamos tipificar de acuerdo a los estamentos del siguiente modo:

a) los relacionados con los(as) académicos(as) se vinculan a materias políticas explícitas $^{47}$, a conductas y relaciones interpersonales y a sus funciones;

b) los de los(as) estudiantes a desacatos políticos, copia de pruebas, uso indebido de esténciles, conductas "impropias";

c) las de los(as) funcionarios(as) a robo ${ }^{48}$, conflictos interpersonales y causas políticas.

Estos son los grandes motivos que van produciendo la "narrativa del sumario" y a través de los cuales podemos capturar una climatología, es decir el ambiente que se respiraba, así como la sujeción implacable a los horizontes de "limpieza" que propiciaron los rectores delegados y a los cuales adhirieron las autoridades, académicos(as) y funcionarios(as) gestores y practicantes del "mundo del sumario". Uno de los actores que resalta en este mundo es el fiscal general Julio Salas Romo, cuyo nombre es invocado desde 1973 a 1980 y su firma rubrica, casi emblemáticamente, diversos papeleos, oficios, resoluciones y notificaciones del período ${ }^{49}$. Es interesante constatar que en muchas ocasiones los(as) académicos(as) que eran nombrados fiscales intentaban eludir esa labor aduciendo escaso tiempo para ello debido a sus investigaciones o docencia, solicitudes que con frecuencia eran denegadas (como se apreciará más adelante).

La lectura de los casos da cuenta de una climatología donde las arbitrariedades y la obsesión por el orden y la "moral" tenían cabida casi como en una pesadilla o delirio psicótico. El tópico del robo es tan frecuente que parece librarse una batalla entre las autoridades y parte de la comunidad, por un lado por sancionar y perseguir esa conducta y por el otro, de persistir en la sustracción, con una tenacidad y sistematicidad que podría semejar un boicot o un "revanchismo", un modo de resistencia. Mirado desde la perspectiva del hoy — y de nuestra noción de la durabilidad de los objetos- es sorprendente encontrar sumarios por desaparecimiento de enchufes, válvulas de gas, diversos tipos de cables, corcheteras, probetas, llaves: todo objeto parece contener el signo de

47. En muchos sumarios se observa que tras las causas de conflictos interpersonales se escondían diferencias políticas.

48. El "robo", sin embargo, es un leitmotiv de enorme recurrencia y no solo privativo de los(as) funcionarios(as), los(as) estudiantes también son acusados (as) de sustracciones, sobre todo de pruebas y exámenes. El robo constituye una causal repetitiva que podría ser objeto de una investigación en sí mismo.

49. De acuerdo a Economistas de la U..., se habría instaurado en la Universidad un "sistema judicial" de 36 fiscales y sobre ellos un fiscal general y un tribunal de apelación como última instancia, y "...las sanciones mayores solo podían ser aplicadas por el fiscal general” (op. cit., págs. 222-223). 
su sustracción. Los sumarios por desaparición de dinero son comunes, pero lo son más aquellos ya descritos.

Desde la perspectiva que ofrecen las narrativas de los sumarios, de los decretos y otros documentos encontrados en la bóveda, la vida cotidiana de las oficinas y de las aulas era constantemente vigilada, acechada (como se lee en los testimonios de los sumarios: siempre alguien vio a otro a determinada hora con precisión de reloj, como se podrá confrontar en el robo del anillo que transcribimos más adelante).Sin duda, la "moral" impuesta y la "limpieza" de la Universidad implicaba vigilancia sobre estas conductas cuya atención llama a castigarlas casi tanto como las políticas. Desde allí que el robo pueda entenderse también como estrategia desestabilizadora, como ruptura constante de los límites decretados por la intervención militar y por ende perseguidos con obstinación por parte del poder: hasta la pérdida de un tenedor implicó utilizar el tiempo y las energías de las autoridades en la Sede Osorno, como se lee en esta Resolución exenta No 262, del 5 de junio de 1980:

"Vistos:

a) Nota de la Concesionaria del Casino dirigida a la Comisión casino dando cuenta de la sustracción de un tenedor, señalando como presuntos responsables a los alumnos Felix Kuoquinjoo Silva de la carrera de Ejecución en Acuicultura y María Antonieta Álvarez Contreras de la carrera de Enfermería;

b) Que el hurto de especies por insignificante que ellas sean, importa una alteración a la normal convivencia universitaria y los responsables deben ser ejemplarmente sancionados;

c) Lo dispuesto en el Art. del D.U.448 de 1975

Resuelvo:

1. Instrúyase sumario para establecer la responsabilidad que podrá corresponder a los alumnos relatados en los vistos de esta resolución en los hechos descritos.

2. Designase como fiscal al profesor Sr. Gabriel Venegas Vásquez del Departamento de Humanidades y Arte Grado 8 EUS.

Anótese, comuníquese a quien corresponda y cúmplase.

Víctor Hugo Vergara Giovannini, Vicerrector.

c/c a Sr Fiscal Designado, a Sr. Fiscal General de la U de Chile, a Sr Controlar, Contraloría Interna U de Chile"

La "convivencia universitaria" se veía amenazada incluso por el robo de un simple cubierto: esto grafica la maniática escena del poder y la expansión del atmoterrorismo burocrático con su justificación "moral". ¿ No representa acaso esto una suerte de "opresión administrada burocráticamente"? ?50. Eso es lo que podremos leer, a continuación, en las escenas documentales que hemos seleccionado.

Por último, la revisión de los sumarios y otros documentos que exponemos dan cuenta de los distintos períodos de la refundación de la Universidad de Chile y el impacto de la intervención militar en ella. Así es posible visualizar, grosso modo, dos grandes

50. Así cataloga Zygmunt Bauman al Holocausto a partir de los documentos que dejó de sus crímenes (op. cit., pág. 159). 
momentos: el primero, entre 1973 y 1975, que muestra el desmantelamiento de la comunidad vía los decretos de expulsión, exoneración y vacancias de cargo, así como con la reestructuración de las sedes y los programas de estudio; un segundo que va desde 1975 a 1980 y que pone de manifiesto el acecho y la instalación del atmoterrorismo burocrático a través de los sumarios disciplinantes y las políticas del microterror que pretendían enmarcar las conductas y pensamientos de la comunidad; es al mismo tiempo, un momento donde se instalan incipientemente las políticas de autofinanciamiento, así como las resistencias que se expresan de las más diversas maneras, abiertamente políticas o soterradas. La historia documental que se desencadena a partir de 1981 con la amputación del carácter nacional y del Instituto Pedagógico queda por construirse (y sin duda, también, la que esbozamos en este acápite). La memoria de la Universidad de Chile sigue en deuda con el examen profundo de su pasado reciente, en vistas a la reconfiguración futura de las antiguas solidaridades, símbolos y relatos del pensamiento institucional. 